\title{
Framework of Artificial Intelligence Learning Platform for Education
}

\author{
Junjiraporn Thongprasit $^{1} \&$ Panita Wannapiroon ${ }^{1}$ \\ ${ }^{1}$ King Mongkut's University of Technology North Bangkok, Bangkok, Thailand \\ Correspondence: Junjiraporn Thongprasit, King Mongkut's University of Technology North Bangkok, Bangkok, \\ Thailand.
}

Received: September 1, 2021

Accepted: November 15, 2021

Online Published: January 17, 2022

doi:10.5539/ies.v15n1p76

URL: https://doi.org/10.5539/ies.v15n1p76

\begin{abstract}
Nowadays, Information Technology is an integrated as a part of our life activities. It does not affect only teaching and learning methods at all levels, but also the teaching styles of each teacher with suitable for the digital age. Therefore, the standardized platform should create for all teachers to effectively serve the future education policy. This research aims to synthesize and develop a framework of an artificial intelligence learning platform for education and estimate the framework's suitability. The research is discussed into three phases: 1) synthesizing an intelligent learning platform by using Artificial Intelligence (AI), 2) developing a framework of an artificial intelligence learning platform for education, and 3) evaluating the suitability of the framework by 15 experts. The result found that the suitability evaluation of the framework of an artificial intelligence learning platform for education was very good. The results showed that this framework could develop a learning platform for preparing transformation to the digital age.
\end{abstract}

Keywords: digital learning platform, intelligent learning platform, artificial intelligence

\section{Introduction}

There are many issues to improve the quality of life and one of the important issues is being the quality enhancement in education (Voratitipong et al., 2018). The United Nations (UN) has designated education as one of the 2030 (Sustainable Development Goals: SDGs). The fourth article of the SDGs is on promoting equal education and promoting lifelong learning for everyone (Aroonsrimorakot \& Vajaradul, 2016; Sachs, 2012; United Nations, 2015). From the past to present, education has undergone tremendous changes which affect all our lives. The education does not only end up in the classroom, but it is also changing the pattern to "Learning for life". The pictures of past studies have been replaced with new technology like smart phones, high speed internet, and so on. Today, people around the world can learn online about all topics and can access information from a variety of sources from all over the world. In addition, all students can learn at anytime, anywhere at your convenience through mobile phones, tablets, and computers. When technology comes into a part of our life, it is inevitable that technology will be a key factor in changing the education. The adoption of digital technology as a tool in teaching and learning or known as "Platform of digital learning". It is the learning management that is timed to the changing of the world situation and focus on encouraging people to seek self-knowledge from digital and social media. Consequently, the population in digital age has the ability to create and develop innovative learning to meet the needs of self-learning through the aptitude creation of a free-to-use social learning platform.

The guidelines for developing educational personnel to have the digital skills must be started developing people in equality knowledge and integrating with the knowledge they have by focusing on learning model 70:20:10. This will reduce the lecture and add other relevant learning instead. However, there will be a digital platform to support teaching and learning through information technology systems. Starting with online teaching, which has the trials are widely used, including training to develop teachers' skills and educational personnel can choose the corrected and appropriated technology. This platform can be used as an add-on for teaching and learning and has a positive effect on teachers and learners (Ratchagit, 2019).

Today, technology plays an important role in changing the world. It is not only for the lifestyle of human beings, but it is also included with the response to consumer demand for the business sector and enhancing the efficiency of both public service and the government sector (Institute for Innovative Learning, 2020), in particular, took a role in education. Technology can help to enhance and increase the potential of education, especially "Artificial 
Intelligence or AI". However, artificial intelligence technology does not replace teachers; it is a combination between automation and the instructor's attention. Since learning is not writing code or command systems like a robot, it is personalized learning tailored to the individual student. Everyone has equal access to quality learning, and artificial intelligence technology will greatly promote education which is very useful for students and instructors themselves. In addition, artificial intelligence helps reduce teachers' work time and helps to reduce mistakes that may occur, for example, checking homework or test and creating effective teaching and learning materials. The above examples are causing the application to promote many studies, and it also helps teachers or tutors answer questions for individual students known as "Teacher assistant". It is considered a special channel that allows students to easily consult with teachers and get quick answer (Creative Thailand, 2018; Plook, 2019; Tuemaster, 2020). As previously said, the researcher is interested in developing the framework of an artificial intelligence learning platform for education to help improve the educational system or curriculum to be suitable for changing the world. So that teachers and learners can adjust their lifestyles in a balanced way.

\section{Research Objectives}

- To synthesize the intelligent learning platform using artificial intelligence.

- To develop the framework of an artificial intelligence learning platform for education.

- To estimate the suitability of the framework of an artificial intelligence learning platform for education.

\section{Literature Review}

\subsection{Digital Learning Platform}

A Digital learning platform refers to a learning environment that connects with the learners in two-way by using technology tools to support all or part of the learning. The tools focus on learners and teachers, and software that were designed to provide comprehensive help in the educational process. Likewise, this tool can improve the learning experience of learners as well as makes the learning environment become a digital learning environment with limitless freedom (Artuso \& Graf, 2020; Bujang et al., 2020; Pratsri \& Nilsook, 2020; Faustmann et al., 2019; Iliashenko et al., 2019; Yanga \& Yenb, 2016).

\subsection{Intelligent Learning Platform}

\subsubsection{Definition of an Intelligent Learning Platform}

An intelligent learning platform refers to a learning system designed to create intelligence by focusing on human-computer interaction. Then it is a tool that helps to improve the efficiency of evaluating academic achievement, which analyzes data to monitor learners' technology learning and assessments. Besides, the intelligent learning platform can analyze strengths and weaknesses of learning to improve teachers' teaching level as well as stimulate learners' interest in learning and promote the development of balance learning (Adenowo, 2018; Diao, 2020; Gong, 2020; Yang \& Wu, 2017; Zheng, 2018).

\subsubsection{Elements of an Intelligent Learning Platform}

Table 1. Synthesis of elements of an intelligent learning platform

\begin{tabular}{ll}
\hline Elements & \multicolumn{1}{c}{ References } \\
\hline 1) User & $\begin{array}{l}\text { (Adenowo, 2018; Artuso \& Graf, 2020; Diao, 2020; Faustmann et al., 2019; Gong, 2020; } \\
\text { Iliashenko \& Bikkulova, 2019; Yang \& Wu, 2017; Zheng, 2018) }\end{array}$ \\
\hline 1. Learner & $\begin{array}{l}\text { (Adenowo, 2018; Artuso \& Graf, 2020; Diao, 2020; Faustmann et al., 2019; Gong, 2020; } \\
\text { Iliashenko \& Bikkulova, 2019; Yang \& Wu, 2017; Zheng, 2018) }\end{array}$ \\
\hline 2. Teacher & $\begin{array}{l}\text { (Adenowo, 2018; Artuso \& Graf, 2020; Diao, 2020; Faustmann et al., 2019; Gong, 2020; } \\
\text { Iliashenko \& Bikkulova, 2019; Yang \& Wu, 2017; Zheng, 2018) }\end{array}$ \\
\hline 3. Admin & \\
\hline 2) Learning Platform & (Adenowo, 2018; Artuso \& Graf, 2020; Faustmann et al., 2019; Iliashenko \& Bikkulova, 2019; \\
\hline 1. Learning Content Management Systems & Zheng, 2018) \\
\hline 2. Learning Management Systems & (Iliashenko \& Bikkulova, 2019) \\
\hline 3. Classroom Management System & (Artuso \& Graf, 2020; Iliashenko \& Bikkulova, 2019; Zheng, 2018) \\
\hline 4. Virtual Learning Environments & (Artuso \& Graf, 2020; Awang, 2018; Diao, 2020; Iliashenko \& Bikkulova, 2019) \\
\hline 5. Course Management System & (Artuso \& Graf, 2020; Gong, 2020) \\
\hline
\end{tabular}




\begin{tabular}{ll}
\hline 6. User Management System & $\begin{array}{l}\text { (Artuso \& Graf, 2020; Diao, 2020; Faustmann et al., 2019; Gong, 2020; Iliashenko \& Bikkulova, } \\
\text { 2019; Yang \& Wu, 2017; Zheng, 2018) }\end{array}$ \\
\hline 7. Supporting System & $\begin{array}{l}\text { (Adenowo, 2018; Artuso \& Graf, 2020; Diao, 2020; Faustmann et al., 2019; Gong, 2020; } \\
\text { Iliashenko \& Bikkulova, 2019; Yang \& Wu, 2017; Zheng, 2018) }\end{array}$ \\
\hline 8. Intelligent Tutoring System & (Zheng, 2018) \\
\hline 9. Massive Open Online Course (MOOC) & (Zheng, 2018) \\
\hline 3) Intelligent Technology & \\
\hline 1. Web Service & (Artuso \& Graf, 2020; Faustmann et al., 2019; Gong, 2020; Yang \& Wu, 2017; Zheng, 2018) \\
\hline 2. Mobile Technology & (Yang \& Wu, 2017) \\
\hline 3. Virtual Reality: VR & (Iliashenko \& Bikkulova, 2019) \\
\hline 4. Artificial Intelligence & (Adenowo, 2018; Artuso \& Graf, 2020; Diao, 2020; Iliashenko \& Bikkulova, 2019; Zheng, 2018) \\
\hline 5. Online Classroom & (Gong, 2020) \\
\hline 6. E-learning & (Awang, 2018; Faustmann et al., 2019; Siron, 2020) \\
\hline 7. Embedded Process Monitoring & (Adenowo, 2018) \\
\hline 4) Curriculum & \\
\hline 1. Curriculum & (Artuso \& Graf, 2020; Gong, 2020) \\
\hline 2. Learning Achievement & (Diao, 2020; Gong, 2020) \\
\hline 3. Content & (Artuso \& Graf, 2020; Yang \& Wu, 2017) \\
\hline 4. Supplement of Advance Learning & (Yang \& Wu, 2017) \\
\hline 5. Data Analysis & (Yang \& Wu, 2017) \\
\hline 6. Assessment & (Artuso \& Graf, 2020; Gong, 2020; Yang \& Wu, 2017) \\
\hline 7. Assessment Indicators & (Gong, 2020) \\
\hline 8. Quality Monitoring Students & (Gong, 2020; Yang \& Wu, 2017) \\
\hline 9. Practice & (Diao, 2020) \\
\hline
\end{tabular}

From Table 1, the intelligent learning platform resulting from the synthesis of relevant research can conclude into four components as follows:

1) User: learner, teacher, and admin.

2) Learning platform: learning content management systems, learning management systems, classroom management system, virtual learning environments, course management system, user management system, supporting system, intelligent tutoring system, and Massive Open Online Course (MOOC).

3) Intelligent technology: web service, mobile technology, virtual reality, artificial intelligence, online classroom, E-learning, and embedded process monitoring.

4) Curriculum: curriculum, learning achievement, content, a supplement of advance learning, data analysis, assessment, assessment indicators, quality monitoring students', and practice.

\subsection{Artificial Intelligence for Education}

\subsubsection{Definition of an Artificial Intelligence}

Artificial intelligence refers to technology that simulates human intelligence and behavior to think like humans and imitates human actions (Anagnostopoulou et al., 2020; Maneehaet \& Wannapiroon, 2019; Tang \& Hai, 2021; $\mathrm{Yu}, 2021$ ), which are developed based on working principles and incoming technology. Moreover, it helps in working or making decisions instead of human intervention and working wisely (O'Brien, 2020). It also can recognize, learn, and automate tasks without human command (Copeland, 2020; Frankenfield, 2020; Haenlein, 2019; Hamet \& Tremblay, 2017; Marsden, 2017; Szolovits, 2018; Zhang \& Dafoe, 2019). It aims primarily to make computer performance more comprehensive and cultivate intelligent patterns of thinking linking humans to computers to make them smarter (Han, 2019). As one of the most advanced information technologies globally, Artificial intelligence technology has made many advances in fields such as Speech recognition, Automatic control, Organization management, and Teaching system (Yang et al., 2018).

\subsubsection{Artificial Intelligence Technology}

Artificial intelligence technology can be classified into four types of functionality: reactive machines, limited memory, theory of mind, and self-awareness (Hintze, 2016; Johnson, 2020; Lateef, 2020). Further it can be classified into three types by capabilities: Artificial Narrow Intelligence (ANI), Artificial General Intelligence (AGI), and Artificial Super Intelligence (ASI) (Biswal, 2020; Fourtané, 2019; Joshi, 2019). 


\subsubsection{Artificial Intelligence Technology to Support Learning Platforms}

A learning platform that uses artificial intelligence technology to support is a further step of the education system. On the other hand, there are still many people who may not realize the benefit or the importance of adopting artificial intelligence technology to help develop and improve the education system. Therefore, artificial intelligence technology may not be well known worldwide. There are many benefits to implementing artificial intelligence technology to support learning platforms. It does not only help to shorten the working time, but it also helps to increase the capacity in various tasks that humans cannot do, for example, analysis of the knowledge level of the learners, offering retrospective communication, helping to plan for improvement of the teaching and learning curriculum as well as aiding in teaching and learning to be more effective (Kuprenko, 2020).

\section{Method}

The research method was divided into three phases according to the research objectives as follows:

Phase 1: Synthesis is an artificial intelligence-based intelligent learning platform. To begin, materials and research on digital learning platforms, intelligent learning platforms, and artificial intelligence technology were reviewed. There were forty issues published in the international research-based system between 2016 and 2021 . After that, elements of an intelligent learning platform were synthesized, and artificial intelligence technology was presented in an illustration plan and the essay, as shown in Figure 1 and Figure 2. The research tool validity was analyzed by content analysis.

Phase 2: A framework of an artificial intelligence learning platform for education was developed. The data obtained from research in Phase 1 was used to develop a framework of an artificial intelligence learning platform for education, as presented in an illustration plan and the essay in Figure 4.

Phase 3: The suitability of the framework of an artificial intelligence learning platform for education was evaluated. Use questionnaires as a data collection tool from 15 experts who had more than five years' experience in the relevant field. Therefore, experts were selected, and each of their expertise in the digital learning platform, intelligent learning platform, and artificial intelligence. The research instruments were the framework of artificial intelligence and a learning platform for education. All survey questions utilized a 5-point Likert scale. The arithmetic mean and standard deviation were utilized in the data analysis.

\section{Results of Research}

\subsection{The Results of the Synthesis Documents and Research}

\subsubsection{Elements of Artificial Intelligence Learning Platform}

Artificial intelligent learning platform consisted of four main components: user, learning platform, intelligent technology, and curriculum. Each main component had a different sub-component. The first component was the user, which consisted of a learner, teacher, and admin. The second component was the learning platform, which consisted of a user management system, supporting system, intelligent tutoring system, and Massive Open Online Course (MOOC). The third component was intelligent technology, which consisted of web service, mobile technology, virtual reality, artificial intelligence, online classroom, E-learning, and embedded process monitoring. The last component was the curriculum, which comprises a supplement of advanced learning, data analysis, assessment, assessment indicators, quality monitoring students', and practice. (See Figure 1) 


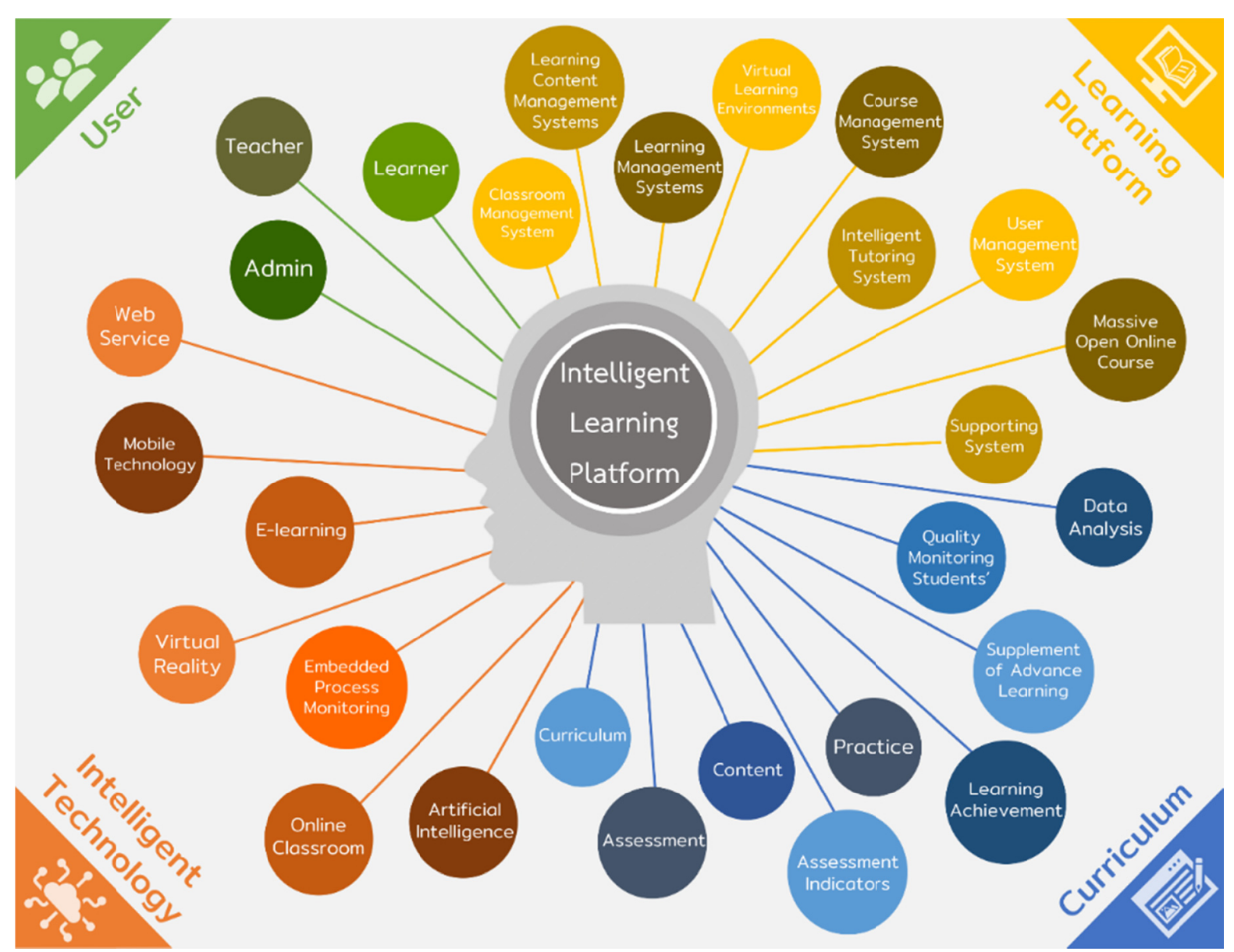

Figure 1. Elements of an intelligent learning platform

\subsubsection{Artificial Intelligence Technology}

Artificial intelligence technology can be classified into four types based on functionality: reactive machines, limited memory, theory of mind, and self-aware, and can be classified into three types regarding capabilities: Artificial Narrow Intelligence (ANI), Artificial General Intelligence (AGI), and Artificial Super Intelligence (ASI) as shown in Figure 2.

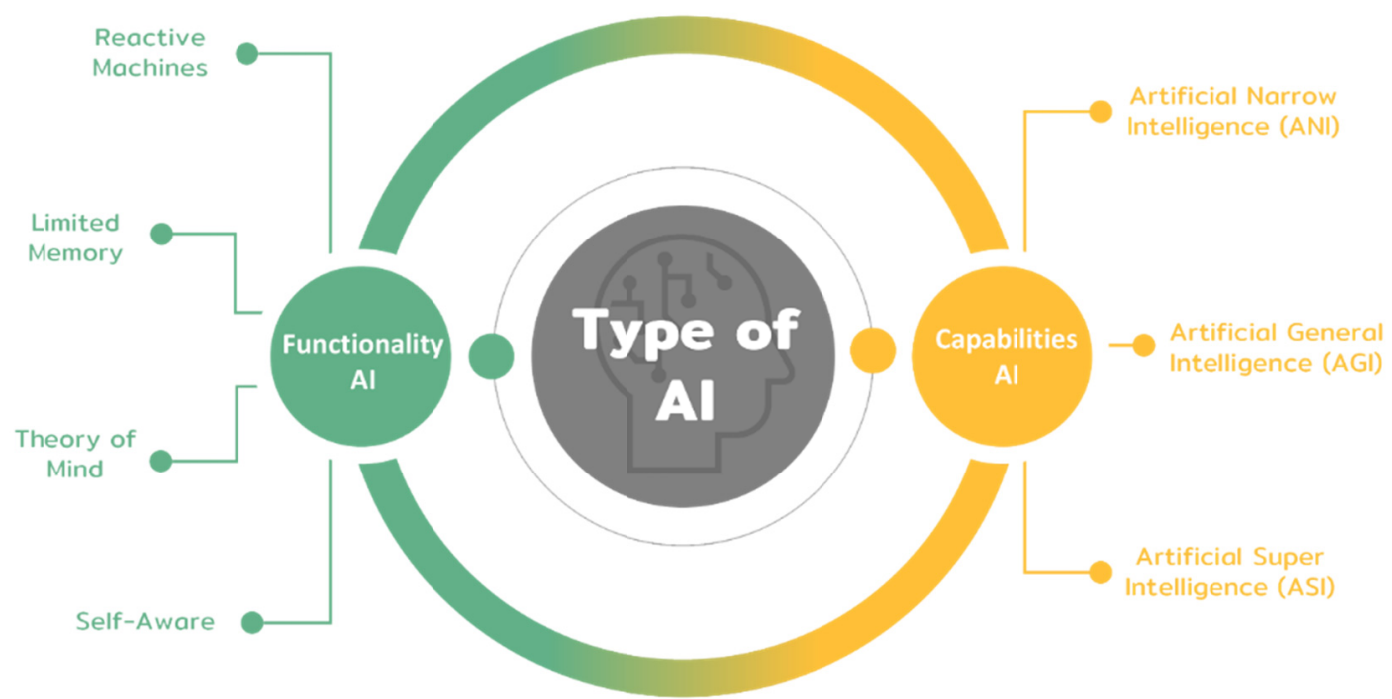

Figure 2. Type of artificial intelligence technology 


\subsection{Framework Design}

This step is the development of a framework of an artificial intelligence learning platform for education, comprising elements of an intelligent learning platform. This includes artificial intelligence technology and intelligent education. Outlined in Figure 1 and Figure 2 are the results of the synthesis of an intelligent learning platform and artificial intelligence technology to develop into an artificial intelligence learning framework, as shown in Figure 3. Then all data was developed into a framework of an artificial intelligence learning platform for education, as presented in Figure 4.

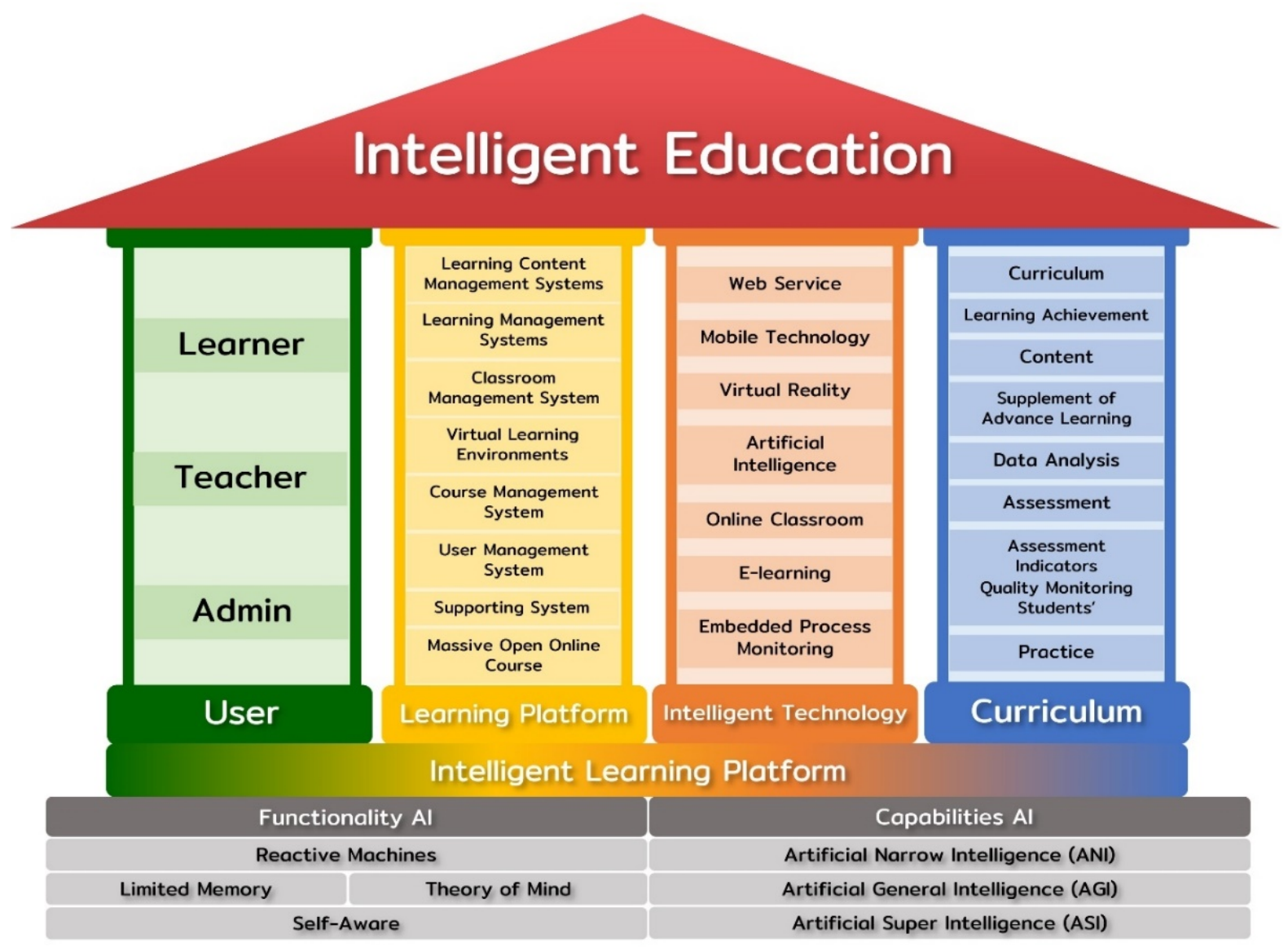

Figure 3. Artificial intelligence learning framework 


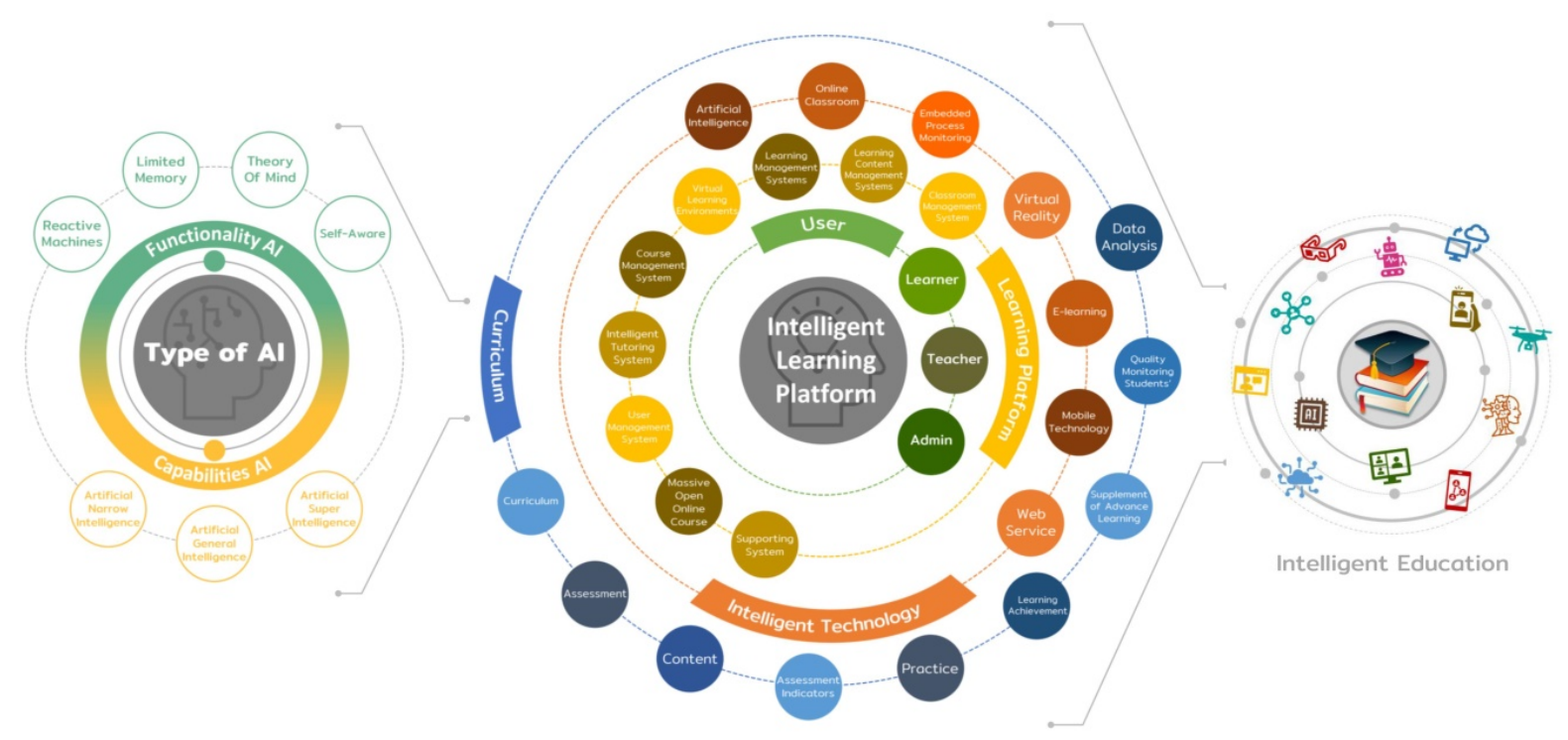

Figure 4. Framework of artificial intelligence learning platform for education

\subsection{The Evaluation Results Platform}

The suitability of the framework of an artificial intelligence learning platform for education was evaluated. The researchers invited 15 experts to carry out an evaluation. The results were shown in Table 2.

Table 2. Suitability of the framework of an artificial intelligence learning platform for education $(n=15)$

\begin{tabular}{lccc}
\hline \multicolumn{1}{c}{ Description } & Result & Rate of \\
\cline { 2 - 3 } Appropriateness
\end{tabular}

Table 2 shows the evaluation by 15 experts regarding the appropriateness of the artificial intelligence learning platform for education. With respect to the evaluation results of the artificial intelligence learning platform for 
education, overall, it was found to be at a very good level (Mean $=4.38$, S.D. $=0.67)$. When examining each component, artificial intelligence was at a very good level (Mean $=4.63$, S.D. $=0.61$ ). Second, an intelligent learning platform was found to be at the optimal level (Mean $=4.27$, S.D. $=0.69)$. Furthermore, intelligent education was found to be at a very good level (Mean $=4.27$, S.D. $=0.59)$. The artificial intelligence learning platform for education was suitable for practical use at a very good level (Mean $=4.38$, S.D. $=0.67)$.

\section{Discussion}

The framework of an artificial intelligence learning platform for education has three elements: artificial intelligence technology, intelligent learning platform, and intelligent education. Based on the research of designing a framework of an artificial intelligence learning platform for education, it can be summarized as follows:

Artificial intelligence technology consists of the following components: functionality AI and capabilities AI. Functionality AI has four types: reactive machines, limited memory, theory of mind, and self-aware. Capabilities AI contains three types: Artificial Narrow Intelligence (ANI), Artificial General Intelligence (AGI), and Artificial Super Intelligence (ASI). Biswal (2020) conducted research on types of Artificial Intelligence that are necessary to learn in 2020. The above elements are made to form an intelligent machine from vast volumes of data to perform human-like tasks. Furthermore, the research on types of Artificial Intelligence conducted by Joshi (2019) indicated that the higher number of the same elements is used in research to make machines emulate humanlike functioning, the higher degree to which an AI system can replicate human capabilities.

Regarding the intelligent learning platform, there must be the following components: user, learning platform, intelligent technology, and curriculum, as seen in the study conducted by Artuso and Graf (2020), who examined the Science and Math courses in a Danish digital learning platform. According to the study, it was found that the digital learning platform must consist of the elements mentioned above. Moreover, in line with the research by Gong (2020), who investigated the evaluation mechanism of learning achievement based on an intelligent learning platform, it will use all the elements mentioned above.

To summarize, intelligent education was the application of artificial intelligence technology and intelligent learning platform, which were used in the education system and enabled the education system to be more intelligent.

From an assessment of 15 experts, they found that an artificial intelligence learning platform framework for education is very suitable. As a result, this platform is suitable and could be used as a framework to develop a learning platform of modern smart education to prepare for the digital transformation.

\section{Conclusion}

In this study, a framework of an artificial intelligence learning platform for education was presented. The findings revealed that thee framework may create a learning platform for preparing the digital era transition. The rise of entry into artificial intelligence technology, educational institutions need to learn, adapt, and develop constantly. When educational institutions are prepared to cope and be aware of the current situation, provide more knowledge, and be always open-minded to learn new things, the education system will probably gain the utmost benefits from using artificial intelligence technology. Artificial intelligence technology could be an important tool for teaching and learning, applied in various fields of instructional management. It is not only to help a teacher manage to learn but also to enable students to learn and expand their knowledge to be more diverse. At present, artificial intelligence technology is the changing and more remarkable field of education. Moreover, teaching and learning through intelligent systems are developed from a small platform as an application in a smart classroom and leading to the development of modern educational structures, which is considered an aid that allows the education system to be more developed.

\section{Acknowledgments}

This research was supported by King Mongkut's University of Technology North Bangkok, Thailand. Thank you to all the experts for supplying support and suggestions that are extremely helpful in this research.

\section{References}

Adenowo, A. (2018). Cognitive process visibility: An embedded process monitoring approach in an intelligent learning module. Engineering and Technology Research Journal, 3(2), 21-33. https://doi.org/10.47545/etrj.2018.3.2.041

Anagnostopoulou, P., Alexandropoulou, V., Lorentzou, G., Lykothanasi, A., Ntaountaki, P., \& Drigas, A. (2020). Artificial intelligence in autism assessment. International Journal of Emerging Technologies in Learning, 15(6), 95-107. https://doi.org/10.3991/ijet.v15i06.11231 
Aroonsrimorakot, S., \& Vajaradul, Y. (2016). UN sustainable development goals: 17 aspects for future world. Journal of Thai Interdisciplinary Research, 11(3), 1-7. https://doi.org/10.14456/jtir.2016.3

Artuso, A. R., \& Graf, S. T. (2020). Science and math courses in a Danish digital learning platform - What makes them more or less popular?. IARTEM Journal, 12(1), 1-35. https://doi.org/10.21344/iartem.v12i1.726

Awang, H., Aji, Z. M., Yaakob, M. F. M., Osman, W. R. S., Mukminin, A., \& Habibi, A. (2018). Teachers' intention to continue using virtual learning environment (VLE): Malaysian context. Journal of Technology and Science Education, 8(4), 439-452. https://doi.org/10.3926/jotse.463

Biswal, A. (2020). 7 types of Artificial Intelligence that you should know in 2020. Simplilearn Solutions. https://www.simplilearn.com/tutorials/artificial-intelligence-tutorial/types-of-artificial-intelligence

Bujang, S. D. A., Selamat, A., Krejcar, O., Maresova, P., \& Nguyen, N. T. (2020). Digital learning demand for future education 4.0-case studies at Malaysia education institutions. Informatics, 7(2), 1-11. https://doi.org/10.3390/informatics7020013

Copeland, B. J. (2020). Artificial Intelligence. Encyclopædia Britannica.

Creative Thailand. (2018). When AI changes the education. Creative Thailand. Retrieved from https://web.tcdc.or.th/th/Articles/Detail/\%25E0\%25B9\%2580\%25E0\%25B8\%25A1\%25E0\%25B8\%25B7 $\% 25 \mathrm{E} 0 \% 25 \mathrm{~B} 9 \% 2588 \% 25 \mathrm{E} 0 \% 25 \mathrm{~B} 8 \% 25 \mathrm{AD}-\mathrm{AI}-\% 25 \mathrm{E} 0 \% 25 \mathrm{~B} 9 \% 2580 \% 25 \mathrm{E} 0 \% 25 \mathrm{~B} 8 \% 259 \mathrm{~B} \% 25 \mathrm{E} 0 \% 25 \mathrm{~B}$ $8 \% 25 \mathrm{~A} 5 \% 25 \mathrm{E} 0 \% 25 \mathrm{~B} 8 \% 25 \mathrm{~B} 5 \% 25 \mathrm{E} 0 \% 25 \mathrm{~B} 9 \% 2588 \% 25 \mathrm{E} 0 \% 25 \mathrm{~B} 8 \% 25 \mathrm{~A} 2 \% 25 \mathrm{E} 0 \% 25 \mathrm{~B} 8 \% 2599 \% 25 \mathrm{E} 0 \% 2$ $5 \mathrm{~B} 9 \% 2582 \% 25 \mathrm{E} 0 \% 25 \mathrm{~B} 8 \% 25$

Diao, S. (2020). The reform of teaching management mode based on artificial intelligence in the era of big data. Journal of Physics: Conference Series, 1533(4), 1-7. https://doi.org/10.1088/1742-6596/1533/4/042050

Faustmann, G., Lemke, C., Kirchner, K., Monett, D., Lemke, C., \& Kirchner, K. (2019). Which factors make digital learning platforms successful?. 13th Annual International Technology, Education and Development Conference, 6777-6786. https://doi.org/10.21125/inted.2019.1651

Fourtané, S. (2019). The three types of Artificial Intelligence: Understanding AI. Interesting Engineering, Inc. Retrieved from https://interestingengineering.com/the-three-types-of-artificial-intelligence-understandingai

Frankenfield, J. (2020). Artificial Intelligence (AI). Investopedia. Retrieved from https://www.investopedia.com/terms/a/artificial-intelligence-ai.asp

Gong, X. (2020). Evaluation mechanism of learning achievement based on intelligent learning platform. Journal of Physics: Conference Series, 1550(3), 1-6. https://doi.org/10.1088/1742-6596/1550/3/032063

Haenlein, M. (2019). A brief history of artificial intelligence: On the past, present, and future of artificial intelligence. California Management Review, 61(4). https://doi.org/10.1177/0008125619864925

Hamet, P., \& Tremblay, J. (2017). Artificial intelligence in medicine. Metabolism, 69, s36-s40. https://doi.org/10.1016/j.metabol.2017.01.011

Han, B. (2019). Application of artificial intelligence in autonomous English learning among college students. International Journal of Emerging Technologies in Learning, 14(6), 63-74. https://doi.org/10.3991/ijet.v14i06.10157

Hintze, A. (2016). Understanding the Four Types of Artificial Intelligence. GovTech. Retrieved from https://www.govtech.com/computing/Understanding-the-Four-Types-of-Artificial-Intelligence.html

Iliashenko, O., Bikkulova, Z. U., \& Dubgorn, A. (2019). Development of the University's business model with the use of a digital learning platform. International Conference on Digital Transformation in Logistics and Infrastructure (ICDTLI 2019), 263-268. https://doi.org/10.2991/icdtli-19.2019.47

Institute for Innovative Learning. (2020). Artificial Intelligence (AI) transforms education. Institute for Innovative Learning. Retrieved from https://il.mahidol.ac.th/th/newsletter53-article2/

Johnson, J. (2020). 4 Types of Artificial Intelligence. BMC Software, Inc. Retrieved from https://www.bmc.com/blogs/artificial-intelligence-types/

Joshi, N. (2019). 7 Types of Artificial Intelligence. Frobes. Retrieved from https://www.forbes.com/sites/cognitiveworld/2019/06/19/7-types-of-artificial-intelligence/?sh=4b6bfa7b23 $3 \mathrm{e}$

Kuprenko, V. (2020). Artificial Intelligence in education: benefits, challenges, and use cases. Retrieved from 
https://pub.towardsai.net/artificial-intelligence-in-education-benefits-challenges-and-use-cases-db52d8921f $7 \mathrm{a}$

Lateef, Z. (2020). Types of artificial intelligence you should know. Brain4ce Education Solutions Pvt. Ltd. Retrieved from https://www.edureka.co/blog/types-of-artificial-intelligence/\#Types

Maneehaet, S., \& Wannapiroon, P. (2019). A digital learning ecosystem with artificial intelligence for smart learning. Journal of Education Naresuan University, 21(2), 359-373.

Marsden, P. (2017). Artificial intelligence defined: Useful list of popular definitions from business and science. Retrieved from https://digitalwellbeing.org/artificial-intelligence-defined-useful-list-of-popular-definitionsfrom-business-and-science/

O'Brien, C. (2020). Industry 4 and the future of smart manufacturing. Applied Science and Engineering Progress, 14(1), 1-2. https://doi.org/10.14416/J.ASEP.2020.09.002

Plook. (2019). AI and education promotion. Retrieved from https://www.trueplookpanya.com/blog/content/ 75968/-blog-teaartedu-teaart-

Pratsri, S., \& Nilsook, P. (2020). Design on big data platform-based in higher education institute. Higher Education Studies, 10(4), 36-43. https://doi.org/10.5539/hes.v10n4p36

Ratchagit, T. (2019). Increase organizational potential with a learning model and formula development 70:20:10. https://th.hrnote.asia/orgdevelopment/190620-model-70-20-10/

Sachs, J. D. (2012). From millennium development goals to sustainable development goals. The Lancet, 379(9832), 2206-2211. https://doi.org/10.1016/S0140-6736(12)60685-0

Siron, Y., Wibowo, A., \& Narmaditya, B. S. (2020). Factors affecting the adoption of e-learning in indonesia: Lesson from COVID-19. Journal of Technology and Science Education, 10(2), 282-295. https://doi.org/10.3926/jotse.1025

Szolovits, P. (2018). Artificial intelligence in medicine. England: Routledge.

Tang, J., \& Hai, L. (2021). Construction and exploration of an intelligent evaluation system for educational APP through artificial intelligence technology. International Journal of Emerging Technologies in Learning, 16(5), 17-31. https://doi.org/10.3991/ijet.v16i05.20293

Tuemaster. (2020). AI and education in the future. Retrieved from https://tuemaster.com/blog/aiand-education-in-the-future

United Nations. (2015). The global goals for sustainable development. United Nations. Retrieved from https://www.un.or.th/globalgoals/th/the-goals/

Voratitipong, A., Wannapiroon, P. \& Nilsook, P. (2018). The study of digital technology model for education Basic education. Veridian E-Journal, 11(2), 1200-1215.

Yang, H. S., \& Wu, J. P. (2017). Exploration on cultivation of application-oriented and innovative talents in the information field under "Internet +" environment. Eurasia Journal of Mathematics, Science and Technology Education, 13(8), 5607-5614. https://doi.org/10.12973/eurasia.2017.01014a

Yang, J., Yuan, Y., Zhang, X., Shao, L. Gong, L., Mi, J., \& Xu, T. (2018). A deep learning-based image recognition algorithm for fecal shape of domestic rabbits. Computer Science, 32(SI), 67-78. https://doi.org/10.3166/ria.32.s1.67-78

Yanga, J.-Y., \& Yenb, Y.-C. (2016). College students' perspectives of E-learning system use in high education. Asian Journal of Education and Training, 2(2), 53-62. https://doi.org/10.20448/journal.522/2016.2.2/522.2.53.62

Yu, J. (2021). Academic performance prediction method of online education using random forest algorithm and artificial intelligence methods. International Journal of Emerging Technologies in Learning, 16(5), 45-57. https://doi.org/10.3991/ijet.v16i05.20297

Zhang, B., \& Dafoe, A. (2019). Artificial Intelligence: American attitudes and trends. Center for the Governance of AI, Future of Humanity Institute, University of Oxford. https://doi.org/10.2139/ssrn.3312874

Zheng, S. (2018). Research on the application of big data in the field of online education. Proceedings of the $3 \mathrm{rd}$ International Conference on Information Technology and Industrial Automation (ICITIA 2018), 462-472. https://doi.org/10.12783/dtcse/iciti2018/29137 


\section{Copyrights}

Copyright for this article is retained by the author(s), with first publication rights granted to the journal.

This is an open-access article distributed under the terms and conditions of the Creative Commons Attribution license (http://creativecommons.org/licenses/by/4.0/). 